\title{
Outcomes after radical hysterectomy in patients with early-stage adenocarcinoma of uterine cervix
}

\author{
J-Y Park', D-Y Kim', J-H Kim', Y-M Kim', Y-T Kim' and J-H Nam,,I \\ 'Department of Obstetrics and Gynecology, University of Ulsan College of Medicine, Asan Medical Center, No. 388-I Poongnap-2 dong, Songpa-gu, \\ Seoul 138-736, Korea
}

\begin{abstract}
BACKGROUND: To determine the prognostic factors and treatment outcomes of patients with early-stage adenocarcinoma (AdCa) of uterine cervix who underwent radical hysterectomy $(\mathrm{RH})$.

METHODS: Patients with early-stage squamous cell carcinoma (SCCa) of the uterine cervix who underwent $\mathrm{RH}$ were compared with patients with AdCa by multivariate analysis.

RESULTS: A total of 1218 patients were eligible, of which 996 (81.8\%) had SCCa and 222 (18.2\%) had AdCa. In multivariate analysis, parametrial involvement and lymph node metastasis were significant factors for both recurrence-free survival(RFS) and overall survival (OS) of patients with AdCa, whereas age, tumour size, parametrial involvement and lymph node metastasis were significant factors for both RFS and OS of patients with SCCa. After adjusting for significant prognostic factors, patients with AdCa had significantly poorer RFS (odds ratio $(\mathrm{OR})=2.07,95 \%$ confidence interval $(\mathrm{Cl})=1.37-3.12, \mathrm{P}=0.00 \mathrm{I})$ and $\mathrm{OS}(\mathrm{OR}=2.56,95 \% \mathrm{Cl}=1.65-3.96$, $P<0.00$ I) than patients with SCCa. Recurrence outside the pelvis was more frequent in AdCa than in those with SCCa $(75$ vs $57.8 \%$, $P=0.084)$.

CONCLUSION(S): Although $\mathrm{RH}$ is still acceptable for treatment of patients with AdCa, a more effective systemic adjuvant therapy is required.

British Journal of Cancer (2010) I 02, 1692 - 1698. doi:I0.1038/sj.bjc.6605705 www.bjcancer.com
\end{abstract}

(c) 2010 Cancer Research UK

Keywords: early-stage cervical cancer; squamous cell carcinoma; adenocarcinoma; radical hysterectomy; prognosis

Cervical cancer is the second most common female cancer and the third most common cause of cancer deaths in women worldwide (Parkin et al, 2001; Waggoner, 2003). Approximately 75\% of cervical cancers are squamous cell carcinomas (SCCas) and $15 \%$ are adenocarcinomas (AdCas), and the remainder consists of other rare histologic types (Kosary, 1994; Farley et al, 2003). Recently, however, the relative proportion and the absolute incidence of AdCa, compared with SCCa, have increased (Smith et al, 2000; Liu et al, 2001; Sasieni and Adams, 2001). Nevertheless, there is no uniformly accepted form of management for AdCa. As with SCCa, patients with International Federation of Obstetrics and Gynecology (FIGO) stage IA2 - IIA cervical AdCa are treated by radical hysterectomy (RH). The prognosis of patients with AdCa after $\mathrm{RH}$ is unclear, primarily because studies have been performed on small numbers of patients. Some of these studies found that patients with AdCa have poorer prognosis than do those with SCCa (Hopkins and Morley, 1991; Eifel et al, 1995; Look et al, 1996; Samlal et al, 1997; Lai et al, 1999; Kim et al, 2000; Nakanishi et al, 2000), whereas other reports found no differences in prognosis (AntonCulver et al, 1992; Miller et al, 1993; Shingleton et al, 1995; Grisaru et al, 2001; Ayhan et al, 2004; Lee et al, 2006; Fregnani et al, 2008; Kasamatsu et al, 2009). Therefore, the prognosis after RH and the optimal management of AdCa are still a subject of debate.

*Correspondence: Dr J-H Nam; E-mail: jhnam@amc.seoul.kr Received 5 January 20 10; revised 21 April 20 I0; accepted 26 April 2010
The aim of this study was to clarify the treatment outcomes and prognostic factors after $\mathrm{RH}$ in patients with FIGO stage IA2-IIA AdCa of uterine cervix, and to compare them with those of patients with SCCa to postulate the optimal management of patients with early-stage AdCa of uterine cervix.

\section{MATERIALS AND METHODS}

From 1989 to 2006, 2350 patients with invasive cervical cancer were treated and followed-up at the Asan Medical Center (AMC, Seoul, Korea). After approval by the Institutional Review Board of $\mathrm{AMC}$, we searched the cancer registry and computerised database of AMC for patients with (1) FIGO stage IA2 - IIA cervical cancer, (2) who underwent $\mathrm{RH}$ with pelvic and/or para-aortic lymphadenectomy and (3) who had the histologic types of SCCa and AdCa. Patients who received chemotherapy, radiation therapy (RT) or concurrent chemoradiation therapy (CCRT) before RH, and patients with occult cervical cancer detected after simple hysterectomy, were excluded. As the preferred treatment in our centre for patients with FIGO stage IA2-IIA cervical cancer is $\mathrm{RH}$, almost all patients with FIGO stage IA2-IIA cervical cancer underwent RH and only a small number of patients who were not eligible for radical surgery because of severe medical co-morbidity received RT or CCRT. Radical hysterectomy was completed in patients with positive pelvic or para-aortic lymph nodes or parametrial involvement confirmed by frozen section, although it is still unclear whether the surgeon should complete the $\mathrm{RH}$ or 
Table I Characteristics of the study patients $(n=1218)$

\begin{tabular}{|c|c|c|c|c|}
\hline \multirow[b]{2}{*}{ Characteristics } & \multirow[b]{2}{*}{ Total } & \multirow{2}{*}{$\begin{array}{c}\text { AdCa } \\
(n=222)\end{array}$} & \multirow{2}{*}{$\frac{\text { SCCa }}{(n=996)}$} & \multirow[b]{2}{*}{$P$-value } \\
\hline & & & & \\
\hline \multicolumn{5}{|l|}{ Age, years } \\
\hline Mean (range) & $48.2(24-86)$ & $46.4(25-73)$ & $48.7(24-86)$ & 0.006 \\
\hline$<30$ & $21(1.7 \%)$ & $5(2.3 \%)$ & $16(1.6 \%)$ & 0.177 \\
\hline $30-49$ & $715(58.7 \%)$ & $|4|(63.5 \%)$ & $574(57.6 \%)$ & \\
\hline$>50$ & $482(39.6 \%)$ & $76(34.2 \%)$ & $406(40.8 \%)$ & \\
\hline \multicolumn{5}{|l|}{ FIGO stage } \\
\hline $1 \mathrm{~A} 2$ & $88(7.2 \%)$ & $8(3.6 \%)$ & $80(8.0 \%)$ & 0.061 \\
\hline$|\mathrm{B}|-\mid \mathrm{B} 2$ & $1019(83.7 \%)$ & $195(87.8 \%)$ & $824(82.7 \%)$ & \\
\hline$\| A$ & $111(9.1 \%)$ & $19(8.6 \%)$ & $92(9.3 \%)$ & \\
\hline \multicolumn{5}{|l|}{ Histologic subtype } \\
\hline Mucinous & $203(16.7 \%)$ & $203(16.7 \%)$ & - & - \\
\hline Endometrioid & $14(1.1 \%)$ & $14(1.1 \%)$ & - & \\
\hline Serou & $2(0.2 \%)$ & $2(0.2 \%)$ & - & \\
\hline Mixed & $3(0.2 \%)$ & $3(0.2 \%)$ & - & \\
\hline \multicolumn{5}{|l|}{ Grade of differentiation } \\
\hline Well & $332(27.3 \%)$ & $63(28.4 \%)$ & $269(27.0 \%)$ & 0.366 \\
\hline Moderately & $573(47.0 \%)$ & $94(42.3 \%)$ & $479(48.1 \%)$ & \\
\hline Poorly & $294(24.1 \%)$ & $60(27.0 \%)$ & $234(23.5 \%)$ & \\
\hline Undetermined & $19(1.6 \%)$ & $5(2.3 \%)$ & $14(1.4 \%)$ & \\
\hline \multicolumn{5}{|l|}{ Tumour size, $\mathrm{cm}$} \\
\hline Mean (range) & $2.4(0.3-9)$ & $2.3(0.3-6)$ & $2.4(0.4-9)$ & 0.286 \\
\hline$\leqslant 2$ & $57 \mid(46.9 \%)$ & $108(48.6 \%)$ & $463(46.5 \%)$ & 0.147 \\
\hline $2-4$ & $510(41.9 \%)$ & $94(42.3 \%)$ & $416(41.8 \%)$ & \\
\hline $4-6$ & $114(9.4 \%)$ & $20(9.0 \%)$ & $94(9.4 \%)$ & \\
\hline$>6$ & $23(1.9 \%)$ & $0 .(0.0 \%)$ & $23(2.3 \%)$ & \\
\hline \multicolumn{5}{|c|}{ Depth of stromal invasion } \\
\hline$\leqslant 1 / 2$ & $753(61.8 \%)$ & | 35 (60.8\%) & $618(62.0 \%)$ & 0.731 \\
\hline$>1 / 2$ & $465(38.2 \%)$ & $87(39.2 \%)$ & $378(38.0 \%)$ & \\
\hline \multicolumn{5}{|c|}{ Parametrial involvement } \\
\hline No & 1106 (90.8\%) & $200(90.1 \%)$ & $906(91.0 \%)$ & 0.684 \\
\hline Yes & $112(9.2 \%)$ & $22(9.9 \%)$ & $90(9.0 \%)$ & \\
\hline \multicolumn{5}{|l|}{ Resection margin } \\
\hline Negative & I 190 (97.7\%) & $218(98.2 \%)$ & 972 (97.6\%) & 0.585 \\
\hline Positive & $28(2.2 \%)$ & $4(1.8 \%)$ & $24(2.4 \%)$ & \\
\hline \multicolumn{5}{|l|}{ LVSI } \\
\hline No & $969(79.6 \%)$ & $189(85.1 \%)$ & $780(78.3 \%)$ & 0.023 \\
\hline Yes & $249(20.4 \%)$ & $33(14.9 \%)$ & $216(21.7 \%)$ & \\
\hline \multicolumn{5}{|c|}{ Lymph node metastasis } \\
\hline No & $1048(86.0 \%)$ & $188(84.7 \%)$ & $860(86.3 \%)$ & 0.518 \\
\hline Yes & $170(14.0 \%)$ & $34(15.3 \%)$ & $136(13.7 \%)$ & \\
\hline \multicolumn{5}{|l|}{ PALN metastasis ${ }^{\mathrm{a}}$} \\
\hline No & 1204 (98.9\%) & $219(98.6 \%)$ & 985 (98.9\%) & 0.755 \\
\hline Yes & $14(1.1 \%)$ & $3(1.4 \%)$ & II (I.1\%) & \\
\hline \multicolumn{5}{|l|}{ Adjuvant treatment } \\
\hline None & $907(74.5 \%)$ & $159(71.6 \%)$ & $748(75.1 \%)$ & 0.242 \\
\hline Chemotherapy & $86(7.1 \%)$ & $20(9.0 \%)$ & $66(6.6 \%)$ & \\
\hline Radiation therapy & $113(9.3 \%)$ & $26(11.7 \%)$ & 87 (8.7\%) & \\
\hline CCRT & $112(9.2 \%)$ & $17(7.7 \%)$ & $95(9.5 \%)$ & \\
\hline
\end{tabular}

Abbreviations: $\quad$ AdCa = adenocarcinoma; $\quad$ CCRT = concurrent chemoradiation therapy; $\mathrm{FIGO}=$ International Federation of Obstetrics and Gynecology; LVSI = lymphovascular space invasion; PALN = para-aortic lymph node; $\mathrm{SCCa}=$ squamous cell carcinoma. ${ }^{a} A$ total of 731 patients underwent para-aortic lymphadenectomy.

stop the procedure and administer CCRT if a frozen biopsy reveals parametrial involvement or lymph node metastasis. Patients with $>2$ intermediate risk factors (lymphovascular space invasion
Table 2 The anatomic location of tumour at first recurrence by histologic type of tumour $(N=122)$

\begin{tabular}{|c|c|c|c|}
\hline \multirow{2}{*}{$\begin{array}{l}\text { Location of } \\
\text { tumour }\end{array}$} & \multicolumn{2}{|c|}{ Histologic type } & \multirow[b]{2}{*}{ Total } \\
\hline & SCCa & $\mathrm{AdCa}$ & \\
\hline Pelvis & $38(42.2 \%)$ & $8(25.0 \%)$ & $46(37.7 \%)$ \\
\hline Outside pelvis & $62(67.8 \%)$ & $24(75.0 \%)$ & $76(62.3 \%)$ \\
\hline Abdomen $^{\mathrm{a}}$ & I (I.1\%) & $7(21.9 \%)$ & $8(6.6 \%)$ \\
\hline Distant metastasis ${ }^{\mathrm{b}}$ & $42(46.7 \%)$ & II (34.4\%) & 53 (43.4\%) \\
\hline $\begin{array}{l}\text { Pelvis and } \\
\text { abdomen }\end{array}$ & $3(3.3 \%)$ & $4(12.5 \%)$ & 7 (5.7\%) \\
\hline $\begin{array}{l}\text { Pelvis and distant } \\
\text { metastasis }\end{array}$ & $3(3.3 \%)$ & $2(6.3 \%)$ & $5(4.1 \%)$ \\
\hline $\begin{array}{l}\text { Abdomen and } \\
\text { distant metastasis }\end{array}$ & $2(2.2 \%)$ & $0(0 \%)$ & $2(1.6 \%)$ \\
\hline $\begin{array}{l}\text { Pelvis, abdomen and } \\
\text { distant metastasis }\end{array}$ & I (I.1\%) & $0(0 \%)$ & | (0.8\%) \\
\hline Total & $90(100.0 \%)$ & $32(100.0 \%)$ & $122(100.0 \%)$ \\
\hline
\end{tabular}

Abbreviations: $\mathrm{AdCa}=$ adenocarcinoma; $\mathrm{SCCa}=$ squamous cell carcinoma. ${ }^{a}$ Abdominal peritoneal metastasis. ${ }^{b}$ Haematogenous metastasis to extraperitoneal organs.

(LVSI), tumour $>4 \mathrm{~cm}$ or deep cervical stromal invasion $>2$ out of 3) were recommended for adjuvant RT, whereas patients with one or more high-risk factors (resection margin involvement, parametrial involvement or lymph node involvement) were recommended for adjuvant CCRT. This policy for adjuvant therapy has been consistent during study periods. Medical records were retrospectively reviewed, and the following parameters were collected: age, FIGO stage, histology, grade of differentiation, tumour size, depth of cervical stromal invasion, parametrial involvement, resection margin status, lymphovascular space invasion, lymph node metastasis, adjuvant therapy, date of recurrence, location of recurrent disease, treatment at recurrence, and date of death or last follow-up. Pathologic slides were reviewed by two experienced pathologists at our institution. Squamous cell carcinomas were graded histologically as well-differentiated (grade 1; mature squamous cells with abundant keratin, pearl formation and sometimes intercellular bridges), moderately differentiated (grade 2; less abundant cytoplasm, cell borders less distinct, nuclei with greater pleomorphism and high mitotic activity) and poorly differentiated (grade 3; masses and nests of small, primitiveappearing oval cells with scant cytoplasm and hyperchromatic and spindle-shaped nuclei with high mitotic activity).

All patients were followed-up at least every 3 months for the first 2 years, at least every 6 months for the next 3 years and then every year until recurrence or death. Recurrence-free survival (RFS) was defined as the time, in months, from the date of $\mathrm{RH}$ to the date of relapse or censoring, and overall survival (OS) was defined as the time, in months, from the date of $\mathrm{RH}$ to the date of death, last follow-up or censoring.

\section{Statistical analysis}

Frequency distributions were compared using the $\chi^{2}$ and Fisher's exact tests, and mean values were compared between groups using Student's $t$-test. The RFS and OS were estimated using the Kaplan Meier method and groups were compared by the log-rank test for categorical factors and Cox's proportional hazards model for continuous factors, by univariate analysis. All prognostic variables found to be significant in univariate analysis were included in multivariate analysis using Cox's proportional hazards model. Stepwise backward elimination methods were used to select factors 
Table 3 Univariate analyses of clinicopathologic parameters on recurrence-free and overall survival in patients with adenocarcinoma

\begin{tabular}{|c|c|c|c|c|c|}
\hline \multirow[b]{3}{*}{ Variables } & \multicolumn{5}{|c|}{$\begin{array}{l}\text { Adenocarcinoma } \\
\quad(n=222)\end{array}$} \\
\hline & \multirow[b]{2}{*}{$N(\%)$} & \multicolumn{2}{|c|}{$\begin{array}{l}\text { Recurrence-free } \\
\text { survival }\end{array}$} & \multicolumn{2}{|c|}{$\begin{array}{l}\text { Overall } \\
\text { survival }\end{array}$} \\
\hline & & $\begin{array}{l}5 \text {-year } \\
\text { rate (\%) }\end{array}$ & $P$-value & $\begin{array}{l}5 \text {-year } \\
\text { rate (\%) }\end{array}$ & $P$-value \\
\hline \multicolumn{6}{|l|}{ Age, years } \\
\hline \multicolumn{5}{|l|}{ variable } & 0.073 \\
\hline$<30$ & $5(2.3)$ & 80 & 0.250 & 80 & 0.096 \\
\hline $30-49$ & $|4|(63.5)$ & 89 & & 93 & \\
\hline$>50$ & $76(34.2)$ & 81 & & 86 & \\
\hline \multicolumn{6}{|l|}{ FIGO stage } \\
\hline $\mathrm{A} 22^{\circ}$ & $8(3.6 \%)$ & 100 & $<0.001$ & 100 & $<0.001$ \\
\hline$|\mathrm{B}|-\mid \mathrm{B} 2$ & 195 (87.8\%) & 89 & & 92 & \\
\hline$\| \mathrm{A}$ & $19(8.6 \%)$ & 52 & & 65 & \\
\hline \multicolumn{6}{|l|}{ Histologic subtype } \\
\hline Mucinous & $203(16.7 \%)$ & 87 & 0.373 & 90 & 0.425 \\
\hline Endometrioid & $14(1.1 \%)$ & 77 & & 84 & \\
\hline Serou & $2(0.2 \%)$ & 50 & & 50 & \\
\hline Mixed & $3(0.2 \%)$ & 100 & & 100 & \\
\hline \multicolumn{6}{|c|}{ Grade of differentiation $^{\mathrm{a}}$} \\
\hline Well & $63(29.0)$ & 88 & 0.688 & 90 & 0.532 \\
\hline Moderately & $94(43.3)$ & 83 & & 91 & \\
\hline Poorly & $60(27.6)$ & 87 & & 89 & \\
\hline \multicolumn{6}{|l|}{ Tumour size, $\mathrm{cm}$} \\
\hline$\leqslant 2$ & $108(48.6)$ & 91 & 0.041 & 95 & 0.033 \\
\hline $2-4$ & $94(42.3)$ & 82 & & 85 & \\
\hline $4-6$ & $20(9.0)$ & 77 & & 90 & \\
\hline$>6$ & $0(0.0)$ & - & & - & \\
\hline \multicolumn{6}{|c|}{ Depth of stromal invasion } \\
\hline$\leqslant 1 / 2$ & I 35 (60.8) & 92 & 0.002 & 94 & 0.008 \\
\hline$>1 / 2$ & $87(39.2)$ & 78 & & 84 & \\
\hline \multicolumn{6}{|c|}{ Parametrial involvement } \\
\hline No & $200(90.1)$ & 89 & $<0.001$ & 92 & $<0.001$ \\
\hline Yes & $22(9.9)$ & 55 & & 66 & \\
\hline \multicolumn{6}{|l|}{ Resection margin } \\
\hline Negative & $218(98.2)$ & 87 & 0.013 & 91 & 0.005 \\
\hline Positive & $4(1.8)$ & 38 & & 38 & \\
\hline \multicolumn{6}{|l|}{ LVSI } \\
\hline No & $189(85.1)$ & 88 & 0.033 & 92 & 0.026 \\
\hline Yes & $33(14.9)$ & 75 & & 80 & \\
\hline \multicolumn{6}{|c|}{ Lymph node metastasis } \\
\hline No & I 88 (84.7) & 90 & $<0.001$ & 94 & $<0.001$ \\
\hline Yes & $34(15.3)$ & 66 & & 69 & \\
\hline \multicolumn{6}{|l|}{ Adjuvant treatment } \\
\hline None & I59 (7I.6) & 89 & 0.003 & 94 & $<0.001$ \\
\hline Chemotherapy & $20(9.0)$ & 88 & & 95 & \\
\hline Radiation therapy & $26(11.7)$ & 76 & & 77 & \\
\hline CCRT & II (7.7) & 71 & & 70 & \\
\hline
\end{tabular}

Abbreviations: $C C R T=$ concurrent chemoradiation therapy; $F I G O=$ International Federation of Obstetrics and Gynecology; LVSI = lymphovascular space invasion.

${ }^{\mathrm{a}} \mathrm{G}$ rade of differentiation was undetermined in 21 patients.

for inclusion in the multivariate Cox proportional hazards model (inclusion criteria, $P<0.05$; exclusion criteria, $P>0.1$ ). $P$-values $<0.05$ in two-sided tests were regarded as significant. Data
Table 4 Univariate analyses of clinicopathologic parameters on recurrence-free and overall survival in patients with squamous cell carcinoma

\begin{tabular}{|c|c|c|c|c|c|}
\hline \multirow[b]{3}{*}{ Variables } & \multicolumn{5}{|c|}{ Squamous cell carcinoma $(n=996)$} \\
\hline & \multirow[b]{2}{*}{$\mathbf{N}$} & \multicolumn{2}{|c|}{$\begin{array}{l}\text { Recurrence-free } \\
\text { survival }\end{array}$} & \multicolumn{2}{|c|}{$\begin{array}{l}\text { Overall } \\
\text { survival }\end{array}$} \\
\hline & & $\begin{array}{l}5 \text {-year } \\
\text { rate (\%) }\end{array}$ & $P$-value & $\begin{array}{l}5 \text {-year } \\
\text { rate (\%) }\end{array}$ & $P$-value \\
\hline \multicolumn{6}{|l|}{ Age, years } \\
\hline $\begin{array}{l}\text { As continuous } \\
\text { variable }\end{array}$ & $996(100)$ & & $<0.00 \mid$ & & $<0.001$ \\
\hline$<30$ & $16(1.6)$ & 94 & $<0.001$ & 94 & $<0.001$ \\
\hline $30-49$ & $574(57.6)$ & 94 & & 97 & \\
\hline$>50$ & $406(40.8)$ & 88 & & 91 & \\
\hline \multicolumn{6}{|l|}{ FIGO stage } \\
\hline $\mathrm{IA} 2$ & $80(8.0)$ & 100 & 0.002 & 100 & 0.061 \\
\hline$|\mathrm{B}|-\mid \mathrm{B} 2$ & $824(82.7)$ & 92 & & 94 & \\
\hline$\| \mathrm{A}$ & $92(9.3)$ & 83 & & 91 & \\
\hline \multicolumn{6}{|c|}{ Grade of differentiation $^{\mathrm{a}}$} \\
\hline Well & $269(27.4)$ & 92 & 0.705 & 93 & 0.896 \\
\hline Moderately & $479(48.8)$ & 92 & & 94 & \\
\hline Poorly & $234(23.8)$ & 90 & & 93 & \\
\hline \multicolumn{6}{|l|}{ Tumour size, $\mathrm{cm}$} \\
\hline$\leqslant 2$ & $463(46.5)$ & 97 & $<0.001$ & 98 & $<0.001$ \\
\hline $2-4$ & $416(41.8)$ & 89 & & 92 & \\
\hline $4-6$ & $94(9.4)$ & 80 & & 87 & \\
\hline$>6$ & $23(2.3)$ & 75 & & 77 & \\
\hline \multicolumn{6}{|c|}{ Depth of stromal invasion } \\
\hline$\leqslant 1 / 2$ & $618(62.0)$ & 94 & $<0.001$ & 95 & 0.001 \\
\hline$>1 / 2$ & $378(38.0)$ & 87 & & 91 & \\
\hline \multicolumn{6}{|c|}{ Parametrial involvement } \\
\hline No & $906(91.0)$ & 93 & $<0.001$ & 95 & $<0.001$ \\
\hline Yes & $90(9.0)$ & 78 & & 82 & \\
\hline \multicolumn{6}{|l|}{ Resection margin } \\
\hline Negative & $972(97.6)$ & 92 & 0.399 & 94 & 0.170 \\
\hline Positive & $24(2.4)$ & 96 & & 100 & \\
\hline \multicolumn{6}{|l|}{ LVSI } \\
\hline No & $780(78.3)$ & 93 & $<0.001$ & 95 & 0.003 \\
\hline Yes & $216(21.7)$ & 87 & & 90 & \\
\hline \multicolumn{6}{|c|}{ Lymph node metastasis } \\
\hline No & $860(86.3)$ & 93 & $<0.001$ & 95 & $<0.001$ \\
\hline Yes & $136(13.7)$ & 82 & & 85 & \\
\hline \multicolumn{6}{|l|}{ Adjuvant treatment } \\
\hline None & $748(75.1)$ & 94 & $<0.001$ & 96 & $<0.001$ \\
\hline Chemotherapy & $66(6.6)$ & 89 & & 91 & \\
\hline Radiation therapy & $87(8.7)$ & 84 & & 87 & \\
\hline CCRT & $95(9.5)$ & 82 & & 85 & \\
\hline
\end{tabular}

Abbreviations: $\mathrm{CCRT}=$ concurrent chemoradiation therapy; $\mathrm{FIGO}=$ International Federation of Obstetrics and Gynecology; LVSI, lymphovascular space invasion. ${ }^{a}$ Grade of differentiation was undetermined in 21 patients.

analyses were performed using SPSS for Windows (version 11.0; SPSS Inc., Chicago, IL, USA). Power calculations were performed using NCSS software (version 2004; NCSS Inc., Kaysville, UT, USA). A two-sided log-rank test with an overall sample size of 1218 subjects (222 in group 1 and 996 in group 2) was calculated to achieve $92 \%$ power at a 0.05 significance level to detect a difference of 0.08 between 0.82 and 0.90 , the proportions surviving in groups 
Table 5 Multivariate analyses of clinicopathologic parameters on recurrence-free and overall survival in patients with adenocarcinoma

\begin{tabular}{|c|c|c|c|c|c|}
\hline \multirow[b]{3}{*}{ Variables } & \multicolumn{5}{|c|}{ Adenocarcinoma $(n=222)$} \\
\hline & \multirow[b]{2}{*}{$\mathbf{N}$} & \multicolumn{2}{|c|}{ Recurrence-free survival ${ }^{\mathrm{a}}$} & \multicolumn{2}{|c|}{ Overall survival $^{\mathbf{a}}$} \\
\hline & & OR $(95 \% \mathrm{Cl})$ & $P$-value & OR (95\% Cl) & $P$-valu \\
\hline \multicolumn{6}{|c|}{ Parametrial involvement } \\
\hline No & $200(90.1)$ & Reference & & Reference & \\
\hline Yes & $22(9.9)$ & $3.46(1.46-8.19)$ & 0.005 & $6.17(2.55-14.95)$ & 0.002 \\
\hline \multicolumn{6}{|c|}{ Lymph node metastasis } \\
\hline No & $188(84.7)$ & Reference & & Reference & \\
\hline Yes & $34(15.3)$ & $2.45(1.14-5.30)$ & 0.022 & $2.79(1.25-6.25)$ & 0.012 \\
\hline
\end{tabular}

Abbreviations: $\mathrm{Cl}=$ confidence interval; $\mathrm{LVSI}=$ lymphovascular space invasion; $\mathrm{OR}=$ odds ratio. ${ }^{\mathrm{a}}$ The analysis included FIGO stage, tumour size, depth of stromal invasion, parametrial involvement, resection margin, LVSI, lymph node metastasis, and adjuvant treatment.

1 and 2, respectively. This corresponded to a hazard ratio of 0.53 . The proportion of patients lost during follow-up was 0.05 . These results were based on the assumption that the hazard rates were proportional.

\section{RESULTS}

During the study period, 1218 patients met all inclusion criteria. Of these, 996 patients $(81.8 \%)$ had SCCa and $222(18.2 \%)$ had AdCa. Of the 222 patients with AdCa, 203 had mucinous-type tumours, 14 had endometrioid-type tumours, 2 had serous-type tumours and 3 had mixed-type tumours. The characteristics of these patients are shown in Table 1. Patients with AdCa were significantly younger than those with SCCa. Lymphovascular space invasion was more frequent is patients with AdCa compared with those with SCCa. However, FIGO stage, grade of differentiation, tumour size, depth of cervical stromal invasion, parametrial involvement, resection margin status and lymph node metastasis did not differ between the two histologic groups.

Patients with FIGO stage IA2 disease $(n=88)$ underwent type II hysterectomy with pelvic and/or para-aortic lymphadenectomy and patients with FIGO stage IB1 - IIA disease $(n=1130)$ underwent type III hysterectomy with pelvic and/or para-aortic lymphadenectomy. Thus, all patients underwent pelvic lymphadenectomy, and 731 underwent para-aortic lymphadenectomy. Of the 1218 patients, $311(25.6 \%)$ received postoperative adjuvant therapy. There were no differences in the proportion of patients who received postoperative adjuvant therapy and in the type of adjuvant therapy between the two histologic groups (Table 1).

\section{Survival and patterns of recurrence in patients with AdCa and SCCa}

The overall median and mean follow-up times were 91 and 83 months (range, 10-236 months) for all patients, respectively, 73 and 81 months (range, 11-231 months), respectively, in patients with AdCa and 85 and 92 months (range, 10-236 months), respectively, in patients with SCCa (AdCa vs SCCa, $P=0.012$ ). Of the 1218 patients, 419 had follow-up durations of $<60$ months, with 137 lost to follow-up for over 1 year at the time of this analysis. Of these, 29 had AdCa and 108 had SCCa, making the rates of loss during follow-up $13.1 \%$ (29 out of 222) for the AdCa group, and $10.8 \%$ (108 out of 996) for the SCCa group $(P=0.344)$. The mean and median follow-up times of patients lost to follow-up were 41 and 43 months (range, 14-59 months), respectively, for the AdCa group, and 43 and 41 months (range, $10-59$ months), respectively, for the SCCa group $(P=0.440)$. The 5 -year and 10-year RFS rates in patients with AdCa were 86 and $82 \%$, respectively, and the 5 -year and 10 -year RFS rates in patients with SCCa were 92 and $90 \%$, respectively $(P=0.009)$. The 5 -year and 10-year OS rates in patients with AdCa were 90 and $83 \%$, respectively, and the 5-year and 10 -year OS rates in patients with SCCa were 94 and $91 \%$, respectively $(P<0.001)$. At the time of this analysis, 32 patients (14.4\%) in AdCa group and 90 patients $(9.0 \%)$ in SCCa group had cancer recurrence $(P=0.016)$, and 30 patients $(13.5 \%)$ in AdCa group and 71 patients $(7.1 \%)$ in SCCa died of disease $(P=0.002)$. The mean times to recurrence in the AdCa and SCCa groups were 36 months (range, 6-152 months) and 34 months (range, 2-156 months), respectively $(P=0.805)$. The anatomic location of tumour at first recurrence was outside the pelvis in 57.8 and $75.0 \%$ of patients with SCCa and AdCa, respectively $(P=0.084)$ (Table 2$)$. Recurrent tumours in these patients were observed in the abdomen, skin, muscle, bone, liver, lung, meninx, brain and/or lymph nodes.

The treatment modality or strategy was not altered over time. Therefore, we divided the study period arbitrarily into three 6-year intervals (1989-1994, $n=156 ; 1995-2000, n=371$; and 2001-2006, $n=691$ ). However, we found that 5-year diseasefree survival rates $(95,92$ and $90 \%$, respectively, $P=0.1425)$ and 5 -year OS rates $(97,94$ and $92 \%$, respectively, $P=0.1889)$ did not differ by time.

\section{Prognostic factors associated with RFS and OS in patients with AdCa and SCCa}

In 222 patients with AdCa, FIGO stage, tumour size, depth of cervical stromal invasion, parametrial involvement, resection margin status, LVSI, lymph node metastasis and type of adjuvant treatment were significantly associated with both RFS and OS in univariate analysis, whereas age, grade of differentiation and histologic subtype were unrelated (Table 3). After adjusting for factors significant in univariate analysis, multivariate analysis showed that parametrial involvement and lymph node metastasis were significant factors for both RFS and OS (Table 4).

In 996 patients with SCCa, age, tumour size, depth of cervical stromal invasion, parametrial involvement, LVSI, lymph node metastasis and type of adjuvant treatment were significantly associated with both RFS and OS, but FIGO stage was significantly associated with only RFS in univariate analysis, whereas resection margin status and grade of differentiation were unrelated (Table 5). After adjusting for factors significant in univariate analysis, multivariate analysis showed that age, tumour size, parametrial involvement and lymph node metastasis were significant factors for both RFS and OS (Table 6).

When analysing 1218 patients with AdCa and SCCa, age, FIGO stage, histologic type, tumour size, depth of cervical stromal invasion, parametrial involvement, LVSI, lymph node metastasis and type of adjuvant treatment were significantly associated with both RFS and OS, whereas resection margin status and grade of differentiation were unrelated (Table 7). After adjusting for factors significant in univariate analysis, multivariate analysis showed that age, histologhic type, tumour size, parametrial involvement and lymph node metastasis were significant factors for both RFS and OS (Table 8). Relative to patients with SCCa, the probability of cancer recurrence was significantly higher in patients with $\mathrm{AdCa}$ (odds ratio $(\mathrm{OR})=2.07,95 \%$ confidence interval $(\mathrm{CI})=1.37-3.12, P=0.001)$ after adjusting factors significant in univariate analysis. Moreover, the probability of cancer death was significantly higher in patients with AdCa $(\mathrm{OR}=2.56,95 \% \quad \mathrm{CI}=1.65-3.96, \quad P<0.001)$ compared with patients with SCCa after adjusting factors significant in univariate analysis. 
Table 6 Multivariate analyses of clinicopathologic parameters on recurrence-free and overall survival in patients with squamous cell carcinoma

\begin{tabular}{|c|c|c|c|c|c|}
\hline \multirow[b]{3}{*}{ Variables } & \multicolumn{5}{|c|}{$\begin{array}{c}\text { Squamous cell } \\
\text { carcinoma }(n=996)\end{array}$} \\
\hline & \multirow[b]{2}{*}{$\mathbf{N}$} & \multicolumn{2}{|c|}{$\begin{array}{l}\text { Recurrence-free } \\
\text { survival }^{\mathbf{a}}\end{array}$} & \multicolumn{2}{|c|}{$\begin{array}{l}\text { Overall } \\
\text { survival }^{\mathbf{b}}\end{array}$} \\
\hline & & $\begin{array}{c}\text { OR } \\
(95 \% \mathrm{CI})\end{array}$ & $P$-value & $\begin{array}{c}\text { OR } \\
(95 \% \mathrm{Cl})\end{array}$ & $P$-value \\
\hline \multicolumn{6}{|l|}{ Age, years } \\
\hline $\begin{array}{l}\text { As } \\
\text { continuous } \\
\text { variable }\end{array}$ & $996(100)$ & $1.05(1.03-1.07)$ & $<0.001$ & $1.05(1.03-1.07)$ & $<0.001$ \\
\hline \multicolumn{6}{|c|}{ Tumour size, $\mathrm{cm}$} \\
\hline$\leqslant 2$ & $463(46.5)$ & Reference & & Reference & \\
\hline $2-4$ & $416(41.8)$ & $2.25(1.30-3.89)$ & 0.004 & $2.12(1.16-3.88)$ & 0.015 \\
\hline $4-6$ & $94(9.4)$ & $4.51(2.32-8.78)$ & $<0.001$ & $3.51(1.64-7.50)$ & 0.001 \\
\hline$>6$ & $23(2.3)$ & $6.36(2.43-16.68)$ & $<0.001$ & $5.11(1.73-15.14)$ & 0.003 \\
\hline \multicolumn{6}{|c|}{ Parametrial involvement } \\
\hline No & $906(91.0)$ & Reference & & Reference & \\
\hline Yes & $90(9.0)$ & $1.78(1.01-3.12)$ & 0.046 & $2.17(1.13-4.13)$ & 0.019 \\
\hline \multicolumn{6}{|c|}{ Lymph node metastasis } \\
\hline No & $860(86.3)$ & Reference & & Reference & \\
\hline Yes & $136(13.7)$ & $1.86(1.12-3.09)$ & 0.017 & $2.11(1.18-3.75)$ & 0.012 \\
\hline
\end{tabular}

Abbreviations: $\mathrm{Cl}=$ confidence interval; $\mathrm{LVSI}=$ lymphovascular space invasion; $\mathrm{OR}=$ odds ratio. ${ }^{\text {aThe }}$ analysis included age, FIGO stage, tumour size, depth of stromal invasion, parametrial involvement, LVSI, lymph node metastasis and adjuvant treatment. ' $T$ The analysis included age, tumour size, depth of stromal invasion, parametrial involvement, LVSI, lymph node metastasis and adjuvant treatment.

\section{DISCUSSION}

In our series, the survival outcomes after RH followed by tailored adjuvant therapy according to postoperative risk factors in patients with IA2 - IIA AdCa of uterine cervix were excellent because 5-year RFS and OS were 86 and 90\%, respectively. Parametrial involvement and lymph node metastasis were independent prognostic factors in patients with AdCa as were they in patients with SCCa. Therefore, this treatment strategy for IA2-IIA AdCa of uterine cervix seems acceptable as with SCCa. However, in spite of the distribution of postoperative risk factors, the proportion of patients who received adjuvant therapy, and type of adjuvant therapy were not different between AdCa and SCCa groups, the RFS and OS were significantly poorer in AdCa group compared with SCCa group in multivariate analysis although the survival differences were not much. The time interval to recurrence was not different between AdCa and SCCa groups, but recurrence outside pelvis was more frequent in $\mathrm{AdCa}$ groups. This may suggest that $\mathrm{AdCa}$ has somewhat aggressive behaviour with propensity of distant metastasis and systemic adjuvant therapy might be beneficial for AdCa.

It has long been unclear whether prognosis of patients with early-stage cervical cancer undergoing $\mathrm{RH}$ was dependent on histologic type. Although some studies included a significant number of subjects, most previous reports had small cohorts of patients, with numbers insufficient to determine small differences in RFS and OS. Hence, because the survival of surgically treated patients with early-stage cervical cancer is excellent, the magnitude of differences in RFS and OS among different histologic types is small. Previous studies have reported that the magnitude of differences in 5-year RFS and OS rates ranged from 2.0 to $9.0 \%$, findings similar to ours (Look et al, 1996; Lai et al, 1999; Nakanishi et al, 2000; Ayhan et al, 2004; Fregnani et al, 2008). As far as we know, our series is one of the largest studies which compared the survival outcomes of early-stage AdCa and SCCa. The survival
Table 7 Univariate analyses of clinicopathologic parameters on recurrence-free and overall survival in all patients $(n=1218)$

\begin{tabular}{|c|c|c|c|c|c|}
\hline \multirow[b]{2}{*}{ Variables } & \multirow[b]{2}{*}{$\begin{array}{c}\text { No. of } \\
\text { patients }\end{array}$} & \multicolumn{2}{|c|}{$\begin{array}{l}\text { Recurrence-free } \\
\text { survival }\end{array}$} & \multicolumn{2}{|c|}{$\begin{array}{l}\text { Overall } \\
\text { survival }\end{array}$} \\
\hline & & $\begin{array}{l}5 \text {-year } \\
\text { rate (\%) }\end{array}$ & $P$-value & $\begin{array}{l}5 \text {-year } \\
\text { rate (\%) }\end{array}$ & $P$-value \\
\hline \multicolumn{6}{|l|}{ Age, years } \\
\hline $\begin{array}{l}\text { As continuous } \\
\text { variable }\end{array}$ & $1218(100 \%)$ & & $<0.001$ & & $<0.001$ \\
\hline$<30$ & $21(1.7 \%)$ & 90 & $<0.00$ I & 90 & $<0.001$ \\
\hline $30-49$ & $715(58.7 \%)$ & 93 & & 96 & \\
\hline$>50$ & $482(39.6 \%)$ & 87 & & 90 & \\
\hline \multicolumn{6}{|l|}{ FIGO stage } \\
\hline IA2 & $88(7.2 \%)$ & 100 & $<0.001$ & 100 & $<0.001$ \\
\hline$|\mathrm{B}|-\mid \mathrm{B} 2$ & $1019(83.7 \%)$ & 91 & & 93 & \\
\hline$\| \mathrm{A}$ & $111(9.1 \%)$ & 80 & & 86 & \\
\hline \multicolumn{6}{|l|}{ Histology } \\
\hline SCCa & $996(81.8 \%)$ & 92 & 0.008 & 94 & $<0.001$ \\
\hline $\mathrm{AdCa}$ & $222(18.2 \%)$ & 86 & & 90 & \\
\hline \multicolumn{6}{|c|}{ Grade of differentiation $^{\mathrm{a}}$} \\
\hline Well & $332(27.3 \%)$ & 91 & 0.902 & 93 & 0.967 \\
\hline Moderately & $573(47.0 \%)$ & 91 & & 94 & \\
\hline Poorly & $294(24.1 \%)$ & 89 & & 92 & \\
\hline \multicolumn{6}{|l|}{ Tumour size, $\mathrm{cm}$} \\
\hline$\leqslant 2$ & $57 \mid(46.9 \%)$ & 96 & $<0.001$ & 97 & $<0.001$ \\
\hline $2-4$ & $510(41.9 \%)$ & 88 & & 91 & \\
\hline $4-6$ & $114(9.4 \%)$ & 80 & & 87 & \\
\hline$>6$ & $23(1.9 \%)$ & 75 & & 77 & \\
\hline \multicolumn{6}{|c|}{ Depth of stromal invasion } \\
\hline$\leqslant 1$ out of 2 & $753(61.8 \%)$ & 94 & $<0.001$ & 95 & $<0.001$ \\
\hline$>1$ out of 2 & $465(38.2 \%)$ & 85 & & 90 & \\
\hline \multicolumn{6}{|c|}{ Parametrial involvement } \\
\hline No & I 106 (90.8\%) & 92 & $<0.001$ & 95 & $<0.001$ \\
\hline Yes & $112(9.2 \%)$ & 74 & & 79 & \\
\hline \multicolumn{6}{|l|}{ Resection margin } \\
\hline Negative & 1190 (97.7\%) & 91 & 0.911 & 93 & 0.803 \\
\hline Positive & $28(2.2 \%)$ & 89 & & 93 & \\
\hline \multicolumn{6}{|l|}{ LVSI } \\
\hline No & 1048 (86.0\%) & 92 & $<0.001$ & 94 & $<0.001$ \\
\hline Yes & $170(14.0 \%)$ & 85 & & 89 & \\
\hline \multicolumn{6}{|c|}{ Lymph node metastasis } \\
\hline No & ||||$(85.5 \%)$ & 93 & $<0.001$ & 95 & $<0.001$ \\
\hline Yes & $188(14.5 \%)$ & 78 & & 82 & \\
\hline \multicolumn{6}{|l|}{ Adjuvant treatment } \\
\hline None & 907 (74.5\%) & 93 & $<0.001$ & 95 & $<0.001$ \\
\hline Chemotherapy & $86(7.1 \%)$ & 89 & & 92 & \\
\hline Radiation therapy & $113(9.3 \%)$ & 82 & & 85 & \\
\hline CCRT & $112(9.2 \%)$ & 80 & & 83 & \\
\hline
\end{tabular}

Abbreviations: $\mathrm{AdCa}=$ adenocarcinoma; $\quad \mathrm{CCRT}=$ concurrent chemoradiation therapy; $\quad \mathrm{FIGO}=$ International Federation of Obstetrics and Gynecology; LVSI = lymphovascular space invasion; SCCa $=$ squamous cell carcinoma. ${ }^{\text {a }}$ Grade of differentiation was undetermined in 21 patients.

difference between AdCa and SCCa groups was small but significant. In our series, a two-sided log-rank test with an overall sample size of 1218 subjects (of which 222 are in AdCa group and 996 are in SCCa group) achieved $80 \%$ power at a 0.05 significance level to detect a difference of $6 \%$ in 10-year DFS between 86 and $92 \%$, the proportions surviving in AdCa group and SCCa group, 
Table 8 Multivariate analyses of clinicopathologic parameters on recurrence-free and overall survival in all patients $(n=1218)$

\begin{tabular}{ccccc}
\hline & $\begin{array}{c}\text { Recurrence-free } \\
\text { survival }^{\mathbf{a}}\end{array}$ & & $\begin{array}{c}\text { Overall } \\
\text { survival }^{\mathrm{a}}\end{array}$ \\
\cline { 3 - 5 } Variables & $\begin{array}{c}\text { No. of } \\
\text { patients }\end{array}$ & $\begin{array}{c}\text { OR } \\
(95 \% \mathrm{Cl})\end{array} \quad$ P-value & $\begin{array}{c}\text { OR } \\
(95 \% \mathrm{Cl})\end{array} \quad P$-value \\
\hline
\end{tabular}

\begin{tabular}{lcccc}
\hline $\begin{array}{l}\text { Age, years } \\
\text { As }\end{array}$ & $1218(100 \%)$ & $1.04(1.03-1.06)$ & $<0.001$ & $1.05(1.03-1.06)<0.001$ \\
continuous \\
variable
\end{tabular}

Tumour size, $\mathrm{cm}$

\begin{tabular}{lccrcc}
$\leqslant 2$ & $57 \mid(46.9 \%)$ & Reference & \multicolumn{3}{c}{ Reference } \\
$2-4$ & $510(41.9 \%)$ & $2.11(1.34-3.31)$ & 0.001 & $2.06(1.27-3.37)$ & 0.004 \\
$4-6$ & $114(9.4 \%)$ & $3.55(2.00-6.31)$ & $<0.001$ & $3.02(1.59-5.72)$ & 0.001 \\
$>6$ & $23(1.9 \%)$ & $5.48(2.17-13.81)$ & $<0.001$ & $4.60(1.64-12.93)$ & 0.004
\end{tabular}

Parametrial involvement

No $\quad 1106$ (90.8\%) $\quad$ Reference $\quad$ Reference

Yes $\quad 112(9.2 \%) \quad 2.04(1.27-3.29)$

$0.0032 .15(1.25-3.70)$

0.005

Lymph node metastasis

No $\quad$ III (85.5\%) Reference

Yes $\quad 188(14.5 \%) \quad 2.07(1.35-3.18)$

$0.001 \quad 2.27(1.41-3.64) \quad 0.001$

Abbreviations: $\mathrm{AdCa}$, adenocarcinoma; $\mathrm{Cl}$, confidence interval; $\mathrm{OR}$, odds ratio; LVSI = lymphovascular space invasion; SCCa, squamous cell carcinoma; ${ }^{a}$ The analysis included age, FIGO stage, histology, tumour size, depth of stromal invasion, parametrial involvement, resection margin, LVSI, lymph node metastasis and adjuvant treatment.

respectively. A two-sided log-rank test with an overall sample size of 1218 subjects (of which 222 are in AdCa group and 996 are in SCCa group) achieved $92 \%$ power at a 0.05 significance level to detect a difference of $8 \%$ in 10-year OS between 82 and $90 \%$, the proportions surviving in AdCa group and SCCa group, respectively.

Although we found that patients with AdCa had significantly poorer prognosis than those with SCCa, after adjusting for other significant prognostic factors, the magnitude of differences in RFS and OS were small and the RFS and OS of patients with AdCa and AdSCCa were still good. Therefore, the current management strategy for patients with early-stage AdCa, consisting of $\mathrm{RH}$ followed tailored adjuvant therapy according to postoperative risk factors, should be acceptable.

Of the 20 patients with AdCas $4-6 \mathrm{~cm}$ in diameter, 4 had recurrent disease and 3 of these died of disease within 5 years, making the 5-year DFS and OS rates 77 and $90 \%$, respectively.
The fourth patient with recurrence died of disease at 78 months, making the survival rate at 78 months $80 \%$, similar to the $40-70 \%$ OS rates previously reported.

It is still not clear whether histologic type has an effect on time to recurrence after $\mathrm{RH}$, or on the patterns of spread and recurrence. Although several studies reported that the time to recurrence was shorter in patients with AdCa and AdSCCa than in those with SCCa, more recent work has found no difference associated with histologic type (Look et al, 1996; Lai et al, 1999). When classified into recurrence inside and outside the pelvis, the pattern of spread and recurrence did not differ among histologic groups in some studies (Look et al, 1996; Lai et al, 1999; Grisaru et al, 2001), whereas other reports showed an association between histologic type and more frequent disseminated peritoneal spread or distant metastasis (Drescher et al, 1989; Eifel et al, 1995; Kasamatsu et al, 2009). In our series, recurrence outside the pelvis was more frequent in patients with AdCa. As a result of the absence of curative systemic therapy, patients with recurrence outside the pelvis tend to perform very poorly; however, patients with isolated pelvic recurrence are frequently salvaged with pelvic RT with or without concurrent chemotherapy. This may be one reason for the differences in OS observed among histologic types. Therefore, to improve the survival of patients with AdCa after $\mathrm{RH}$, more effective systemic adjuvant therapies are required.

Consistently reported independent adverse prognostic factors for patients with early-stage cervical cancer after $\mathrm{RH}$ include higher FIGO stage, lymph node metastasis, parametrial involvement, depth of cervical stromal invasion, tumour size and LVSI (Look et al, 1996; Lai et al, 2007; Kasamatsu et al, 2009). We also found that these factors were significant in univariate analysis, although only lymph node metastasis, parametrial involvement and tumour size were significant in multivariate analysis. Some investigators reported that AdCa was more frequently associated with these prognostic factors than SCCa (Kasamatsu et al, 2009). However, other studies found no significant association between these factors and histologic type (Shingleton et al, 1995; Look et al, 1996; Nakanishi et al, 2000; Fregnani et al, 2008). In our series, there were no differences in FIGO stage, tumour size, depth of cervical stromal invasion, parametrial involvement, LVSI or lymph node metastasis between patients with the two histologic types.

In conclusion, we found that the clinicopathologic characteristics and time interval to recurrence did not differ between histologic types. However, recurrence outside the pelvis was more frequent in patients with AdCa than in those with SCCa. Moreover, patients with AdCa had significantly poorer RFS and OS than did those with SCCa. Nevertheless, the current treatment strategy of $\mathrm{RH}$ on patients with AdCa is acceptable because the RFS and OS were still excellent. However, more effective systemic adjuvant therapies after $\mathrm{RH}$ are needed for patients with AdCa.

\section{REFERENCES}

Anton-Culver H, Bloss JD, Bringman D, Lee-Feldstein A, DiSaia P, Manetta A (1992) Comparison of adenocarcinoma and squamous cell carcinoma of the uterine cervix: a population-based epidemiologic study. Am J Obstet Gynecol 166: 1507-1514

Ayhan A, Al RA, Baykal C, Demirtas E, Yuce K, Ayhan A (2004) A comparison of prognoses of FIGO stage IB adenocarcinoma and squamous cell carcinoma. Int J Gynecol Cancer 14: 279-285

Drescher CW, Hopkins MP, Roberts JA (1989) Comparison of the pattern of metastatic spread of squamous cell cancer and adenocarcinoma of the uterine cervix. Gynecol Oncol 33: 340-343

Eifel PJ, Burke TW, Morris M, Smith TL (1995) Adenocarcinoma as an independent risk factor for disease recurrence in patients with stage IB cervical carcinoma. Gynecol Oncol 59: $38-44$

Farley JH, Hickey KW, Carlson JW, Rose GS, Kost ER, Harrison TA (2003) Adenosquamous histology predicts a poor outcome for patients with

advanced-stage, but not early-stage, cervical carcinoma. Cancer 97: $2196-2202$

Fregnani JH, Soares FA, Novik PR, Lopes A, Latorre MR (2008) Comparison of biological behavior between early-stage adenocarcinoma and squamous cell carcinoma of the uterine cervix. Eur J Obstet Gynecol Reprod Biol 136: $215-223$

Grisaru D, Covens A, Chapman B, Shaw P, Colgan T, Murphy J, DePetrillo D, Lickrish G, Laframboise S, Rosen B (2001) Does histology influence prognosis in patients with early-stage cervical carcinoma? Cancer 92: $2999-3004$

Hopkins MP, Morley GW (1991) A comparison of adenocarcinoma and squamous cell carcinoma of the cervix. Obstet Gynecol 77: $912-917$

Kasamatsu T, Onda T, Sawada M, Kato T, Ikeda S, Sasajima Y, Tsuda H (2009) Radical hysterectomy for FIGO stage I-IIB adenocarcinoma of the uterine cervix. Br J Cancer 100: 1400 - 1405 
Kim SM, Choi HS, Byun IS (2000) Overall 5-year survival rate and prognostic factors in patients with stage IB and IIA cervical cancer treated by radical hysterectomy and pelvic lymph node dissection. Int J Gynecol Cancer 10: 305-312

Kosary CL (1994) FIGO stage, histology, histologic grade, age and race as prognostic factors in determining survival for cancers of the female gynecological system: an analysis of 1973-87 SEER cases of cancers of the endometrium, cervix, ovary, vulva, and vagina. Semin Surg Oncol 10: $31-46$

Lai CH, Chang CJ, Huang HJ, Hsueh S, Chao A, Yang JE, Lin CT, Huang SL, Hong JH, Chou HH, Wu TI, Huang KG, Wang CC, Chang TC (2007) Role of human papillomavirus genotype in prognosis of early-stage cervical cancer undergoing primary surgery. J Clin Oncol 25: 3628-3634

Lai CH, Hsueh S, Hong JH, Chang TC, Tseng CJ, Chou HH, Huang KG, Lin JD (1999) Are adenocarcinomas and adenosquamous carcinomas different from squamous carcinomas in stage IB and II cervical cancer patients undergoing primary radical surgery? Int J Gynecol Cancer 9: $28-36$

Lee KB, Lee JM, Park CY, Lee KB, Cho HY, Ha SY (2006) What is the difference between squamous cell carcinoma and adenocarcinoma of the cervix? A matched case-control study. Int J Gynecol Cancer 16: 1569-1573

Liu S, Semenciw R, Mao Y (2001) Cervical cancer: the increasing incidence of adenocarcinoma and adenosquamous carcinoma in younger women. CMAJ 164: $1151-1152$

Look KY, Brunetto VL, Clarke-Pearson DL, Averette HE, Major FJ, Alvarez RD, Homesley HD, Zaino RJ (1996) An analysis of cell type in patients with surgically staged stage IB carcinoma of the cervix: a Gynecologic Oncology Group study. Gynecol Oncol 63: 304-311

Miller BE, Flax SD, Arheart K, Photopulos G (1993) The presentation of adenocarcinoma of the uterine cervix. Cancer 72: 1281-1285

Nakanishi T, Ishikawa H, Suzuki Y, Inoue T, Nakamura S, Kuzuya K (2000) A comparison of prognoses of pathologic stage Ib adenocarcinoma and squamous cell carcinoma of the uterine cervix. Gynecol Oncol 79: $289-293$

Parkin DM, Bray FI, Devesa SS (2001) Cancer burden in the year 2000. The global picture. Eur J Cancer 37(Suppl 8): S4-S66

Samlal RA, van der Velden J, Ten Kate FJ, Schilthuis MS, Hart AA, Lammes FB (1997) Surgical pathologic factors that predict recurrence in stage IB and IIA cervical carcinoma patients with negative pelvic lymph nodes. Cancer 80: $1234-1240$

Sasieni P, Adams J (2001) Changing rates of adenocarcinoma and adenosquamous carcinoma of the cervix in England. Lancet 357: $1490-1493$

Shingleton HM, Bell MC, Fremgen A, Chmiel JS, Russell AH, Jones WB, Winchester DP, Clive RE (1995) Is there really a difference in survival of women with squamous cell carcinoma, adenocarcinoma, and adenosquamous cell carcinoma of the cervix? Cancer 76: 1948-1955

Smith HO, Tiffany MF, Qualls CR, Key CR (2000) The rising incidence of adenocarcinoma relative to squamous cell carcinoma of the uterine cervix in the United States-a 24-year population-based study. Gynecol Oncol 78: $97-105$

Waggoner SE (2003) Cervical cancer. Lancet 361: 2217-2225 